\title{
Expression of intermediate filament proteins in normal and diseased thyroid glands
}

\author{
I D BULEY, K C GATTER, A HERYET, D Y MASON \\ From the Nuffield Department of Pathology, University of Oxford, John Radcliffe Hospital, Oxford
}

SUMMARY A total of 67 samples from normal and pathological thyroid glands were stained (as formalin fixed paraffin sections) with a panel of monoclonal antibodies directed against intermediate filament proteins. The study confirmed previous reports of cytokeratin and vimentin coexpression in primary thyroid carcinomas, but coexpression was also detected in normal thyroid and in a range of benign conditions including follicular adenomas, Hashimoto's thyroiditis, and diffuse hyperplasia (thyrotoxicosis). Prekeratin expression was found (using antibodies recognising higher molecular weight cytokeratins) predominantly in areas of squamous change, independent of the underlying thyroid pathology. This study does not therefore support previous findings that prekeratin expression provides a reliable means of distinguishing follicular pattern papillary carcinoma from follicular carcinoma with its poorer prognosis or that it helps distinguish benign from malignant papillary lesions. No evidence of desmin or neurofilament expression was seen, and in particular, neurofilaments could not be detected in any of the cases of medullary carcinoma studied.

Intermediate filaments are cytoplasmic protein polymers which form part of the cytoskeleton. There are biochemically and immunologically five distinct subtypes of these filaments, and they show a high degree of cell type specificity. Thus cytokeratins occur principally in epithelial cells, vimentin in mesenchymal cells, desmin in muscle cells, neurofilaments in neural cells and glial fibrillary acidic protein in glial cells. ${ }^{1}$ It was initially thought that malignant cells contained the same intermediate filament type as their normal counterpart, and there has therefore been considerable interest in the diagnostic use of intermediate filaments as markers of histogenesis. Recently there have been several accounts of coexpression of intermediate filaments, particularly cytokeratin and vimentin, in a variety of neoplastic lesions. ${ }^{1}$

Among the neoplasms in which coexpression of more than a single intermediate filament type has been observed are primary thyroid tumours. ${ }^{2}$ There have been no comprehensive studies of intermediate filament expression in the full range of normal and neoplastic thyroid lesions, however, and in particular, it is unclear whether neurofilaments are expressed in medullary carcinomas, a neoplasm of neuroendocrine origin.

Accepted for publication 29 July 1986
It has also been reported ${ }^{2-5}$ that antibodies recog nising the higher molecular weight cytokeratins (often referred to as prekeratins $)^{67}$ react preferentially with papillary carcinomas. It has therefore been suggested that these antibodies might be useful in distinguishing papillary carcinoma (particularly the follicular variant) from true follicular carcinoma, and also for distinguishing between benign and malignant papillary thyroid lesions. There has been some controversy, however, as to the validity of this assertion. ${ }^{48}$

In this study a wide range of normal and neoplastic thyroid specimens were stained in routinely fixed paraffin embedded sections with a panel of monoclonal antibodies against different intermediate filament proteins, the aims being to establish the patterns of intermediate filament expression in these thyroid tissues and to evaluate the usefulness of anti-prekeratin antibodies in categorising thyroid malignancies.

\section{Material and methods}

THYROID SPECIMENS

Formalin fixed paraffin embedded blocks from 67 thyroid samples were retrieved from the files of the histopathology department of this hospital.

Thyroid tumours were classified according to the World Health Organisation's International Histologi- 
cal Classification of Tumours, ${ }^{9}$ with recognition of the follicular variant of papillary carcinoma characterised by ground glass nuclei. ${ }^{4}$ The distinction between atypical adenoma and angioinvasive encapsulated follicular carcinoma was made according to the criteria of Lang et al. ${ }^{10}$ Table 1 gives histological details of the tumours studied. Particular points of note are that the eight follicular carcinomas included two angioinvasive encapsulated carcinomas; the 12 papillary carcinomas included two occult tumours (each $2 \mathrm{~mm}$ in diameter); all of the medullary carcinomas showed amyloid deposition and calcitonin staining; the 11 follicular adenomas included areas with embryonal, fetal, normofollicular and macrofollicular patterns; and two of the cases were atypical adenomas.

Hyperplastic thyroid biopsy specimens (14 cases) were all from previous cases of thyrotoxicosis; some cases showed modification of the classical histological pattern by previous iodine treatment. Normal thyroid samples included blocks taken from the nonneoplastic contralateral lobes of cases of thyroid malignancy, tissue removed during block dissections for head and neck malignancies, and thyroid tissue adjacent to the carcinomas and adenomas. Solid cell nests, ${ }^{11}$ possible human ultimobranchial body vestiges, were present in some samples and their staining patterns were noted.

\section{IMMUNOHISTOLOGICAL STAINING}

Sections were immunostained by a three stage immunoperoxidase procedure (following inhibition of endogenous peroxidase activity using methanol containing $\left.1 \% \mathrm{H}_{2} \mathrm{O}_{2}\right)^{12}$ or by the alkaline phosphatase:antialkaline phosphatase (APAAP) technique. $^{13}$

MONOCLONAL ANTIBODIES

The antibodies used in this study included reagents against vimentin, desmin, neurofilaments and a range of cytokeratins (table 2). All of the antibodies had previously been shown to stain reliably routinely processed paraffin embedded tissue. Table 2 indicates the molecular specificities of the anticytokeratin antibodies (detected in immunoblotting experiments). CAM $5 \cdot 2^{14}$ was raised against a colonic carcinoma cell line, it recognises lower molecular weight cytokeratins in secretory epithelia; stratified keratinising epithelia are not stained. $\mathrm{KLl}^{15}$ was raised against human stratum corneum, it recognises higher molecular weight cytokeratins than CAM 5.2 and stains epidermis and other keratinising cells, as well as simple glandular epithelium. The PK series of antibodies (also raised against human stratum corneum) generally recognises higher molecular weight cytokeratins than CAM 5.2 and $\mathrm{KLl}$, which is reflected by the restriction of their immunostaining to normal epidermis and well differentiated foci in squamous tumours.

\section{Results}

Table 1 summarises the results of immunostaining the thyroid specimens with the monoclonal antibodies detailed in table 2. A striking finding was that thyroid epithelium in all specimens, both benign and malignant, was labelled not only by anticytokeratin antibodies (CAM $5 \cdot 2$ and $\mathrm{KL1}$ ) but also in most cases by

Table 2 Details of monoclonal antibodies used in study

\begin{tabular}{lll}
\hline Antibody & Antigen & Reference/source \\
\hline V9 & Vimentin & 16, Dakopatts \\
CAM 5.2 & 39-50KD cytokeratins & 14, Becton-Dickinson \\
KL1 & 55-57KD cytokeratins & 15, Immunotech \\
PK52 & 64-67KD cytokeratins & 17 \\
PK63 & 50-67KD cytokeratins & 17 \\
PK121 & 61-62KD cytokeratins & \\
PK141 & 46-59KD cytokeratins & 18, Euro Diagnostics \\
MNF (2F11) & Neurofilaments & 19, Dakopatts \\
DER11 & Desmin & \\
\hline
\end{tabular}

Table 1 No of cases positively staining

\begin{tabular}{|c|c|c|c|c|c|c|c|c|c|c|}
\hline Thyroid pathology & $\begin{array}{l}\text { No of } \\
\text { cases }\end{array}$ & $V 9$ & $\begin{array}{l}C A M \\
5 \cdot 2\end{array}$ & $K L 1$ & PK52 & PK63 & $P K 121$ & $P K 141$ & $M N F$ & DERII \\
\hline Follicular carcinoma & 8 & 5 & 8 & 8 & 2 & 2 & 2 & 2 & 0 & 0 \\
\hline Papillary carcinoma & 12 & 12 & 12 & 12 & 7 & 7 & 3 & 5 & 0 & 0 \\
\hline Medullary carcinoma & 7 & 3 & 7 & 7 & 0 & $\mathbf{0}$ & 0 & 0 & 0 & 0 \\
\hline Squamous carcinoma & 1 & 1 & 1 & 1 & 1 & 1 & 1 & 1 & 0 & 0 \\
\hline Adenomas & 11 & 8 & 11 & 11 & 2 & 2 & 1 & 0 & 0 & 0 \\
\hline Hyperplasia & 14 & 7 & 14 & 14 & 3 & 3 & 4 & 3 & 0 & 0 \\
\hline Hashimoto's thyroiditis & 9 & 9 & 9 & 9 & 5 & 5 & 4 & 6 & 0 & 0 \\
\hline Hurthle cell hyperplasia & 1 & 0 & 1 & 1 & 0 & 0 & 0 & 0 & 0 & 0 \\
\hline Normals & 5 & 5 & 5 & 5 & 0 & $\begin{array}{l}1 \\
\text { (solid } \\
\text { cell nest) }\end{array}$ & 0 & 0 & 0 & 0 \\
\hline
\end{tabular}



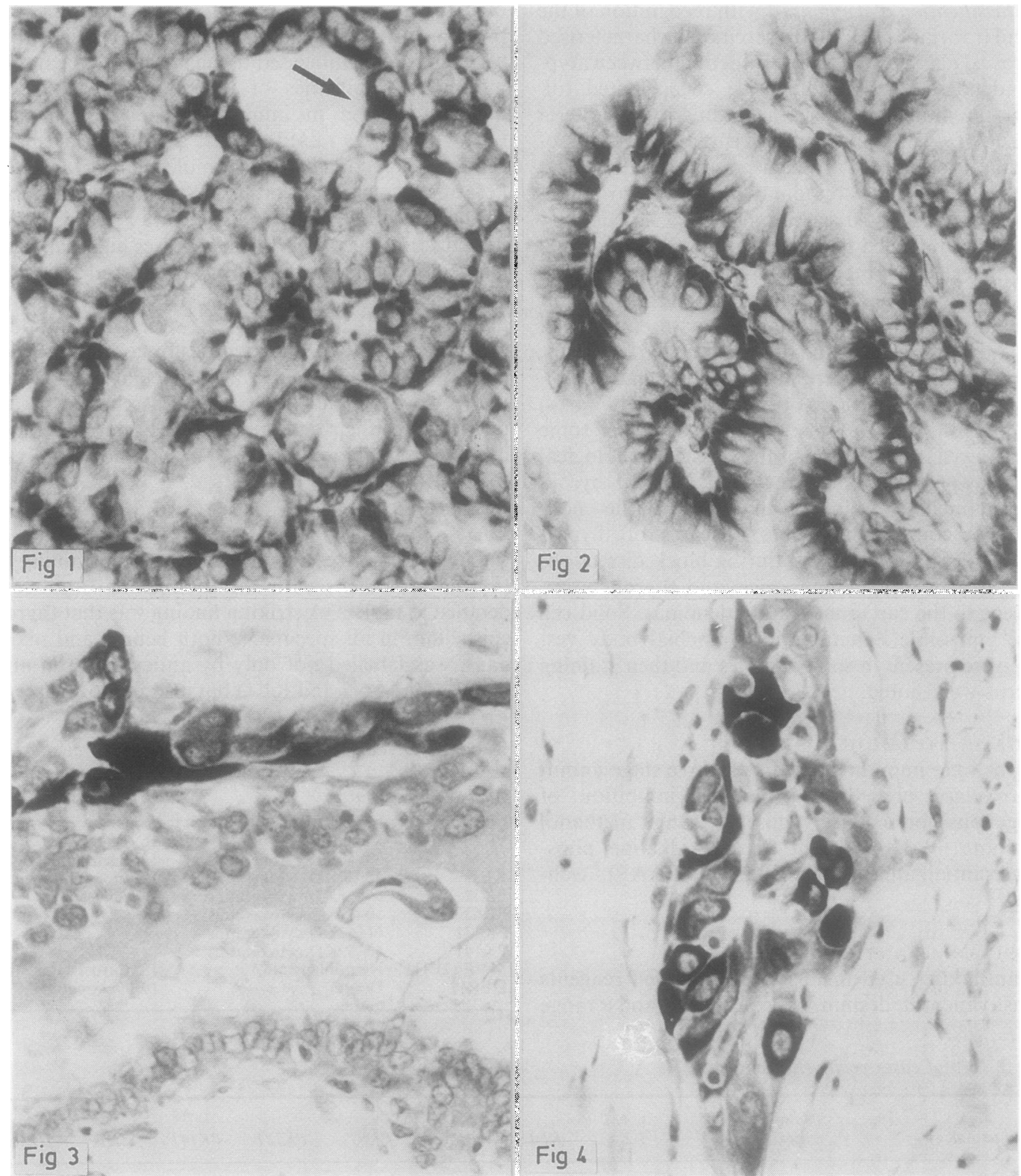

Fig 1 Vimentin expression in follicular carcinoma illustrating both stromal and focal tumour cell staining (arrow).

Fig 2 Vimentin expression in papillary carcinoma with predominantly basal paranuclear staining.

Fig 3 Prekeratin staining (PK63) at periphery of papillary carcinoma.

Fig 4 Prekeratin staining (PK63) of infiltrating island of papillary carcinoma cells set within desmoplastic stroma. 
antivimentin. No cases showed any immunostaining for neurofilament or desmin. Stromal tissue, muscle, and nerve showed the expected patterns of intermediate filament staining in all cases. The immunohistological staining patterns obtained are described below in more detail.

\section{FOLLICULAR CARCINOMAS (EIGHT CASES)}

Tumour cells coexpressed cytokeratin and vimentin in five cases (fig 1). Two cases showed focal staining of higher molecular weight cytokeratins (prekeratins). No difference was noted between the staining pattern of angioinvasive encapsulated carcinomas and nonencapsulated carcinomas.

\section{PAPILLARY CARCINOMAS (12 CASES)}

Twelve cases of papillary carcinoma coexpressed vimentin and cytokeratin (fig 2). The vimentin was often restricted to the subnuclear region but was quite distinct from the stromal staining. Focal staining for higher molecular weight cytokeratins (prekeratins) was seen in eight cases, most noticeably in infiltrating papillary carcinoma elements lying within desmoplastic stroma at the periphery of the tumour (figs 3 and 4). These cells were often in isolated groups and had a squamoid appearance when viewed in conventionally stained sections. Areas of follicular differentiation were present within seven of these papillary tumours but did not show any differences in staining patterns from the papillary areas.

\section{MEDULLARY CARCINOMAS (SEVEN CASES)}

Three cases showed focal areas of cytokeratin and vimentin coexpression. There was no expression of higher molecular weight cytokeratins (prekeratins), and all cases were negative for neurofilaments and desmin.

SQUAMOUS CARCINOMA (ONE CASE)

The single case of squamous cell carcinoma studied coexpressed vimentin and cytokeratins and was also stained by all the antiprekeratin antibodies.

\section{ADENOMAS ( 11 CASES)}

Coexpression of vimentin and cytokeratin was seen in eight cases. Three cases showed focal prekeratin staining. In one of these cases staining was in compressed follicles at the periphery of the adenoma and in another was related to lymphocytic thyroiditis within the tumour. In five of the cases focal lymphocytic thyroiditis was present in the parenchyma next to the adenoma, and all of these cases showed prekeratin staining of cells immediately adjacent to this infiltrate. A similar phenomenon was seen in Hashimoto's thyroiditis (see below). The adenomas, which were categorised histologically as atypical, showed no differences in immunostaining.

\section{HY PER PLASIA (14 CASES)}

Seven cases showed focal staining with antivimentin in addition to anticytokeratins (fig 5), and in five there was weak focal positivity for prekeratins (fig 6). One of the cases included a solid cell nest that stained well with CAM 5.2, KL1, and for prekeratin.

\section{HASHIMOTO'S THYROIDITIS (NINE CASES)}

All nine cases coexpressed vimentin and cytokeratin. Seven cases showed focal prekeratin staining, which was particularly strong in areas adjacent to lymphoid follicles (fig 7). Many but not all of these cells showed Hurthle cell change. A single case of Hurthle cell hyperplasia was negative for vimentin and prekeratin.

\section{NORMAL THYROID (FIVE CASES)}

All samples showed focal coexpression of vimentin and cytokeratins (fig 8). None of the specimens was stained by the anti-prekeratin antibodies. A similar pattern of focal vimentin coexpression was seen in normal thyroid tissue adjacent to many of the neoplasms (benign and malignant) examined in this series. One case included a solid cell nest, which stained as noted in thyroid hyperplasia (see above) for all of the cytokeratins, including prekeratin.

\section{Discussion}

Initial studies of intermediate filament staining suggested that there were no exceptions to the cell type specificity of intermediate filament expression and that malignant cells expressed the same intermediate filaments as their normal counterparts. Coexpression of vimentin and cytokeratin, however, has now been reported in several malignancies, including renal adenocarcinomas, ${ }^{20}$ pleomorphic adenomas of the salivary gland, ${ }^{21}$ mesotheliomas, ${ }^{22}$ nephroblastomas, ${ }^{23}$ synovial sarcomas, ${ }^{24}$ epithelioid sarcomas, ${ }^{25}$ a range of lung tumours, ${ }^{26}$ meningiomas ${ }^{27}$ and isolated epithelial cells in effusions. ${ }^{28}$

This study confirms previous findings of coexpression of vimentin and cytokeratin intermediate filaments in thyroid malignancies. ${ }^{2}$ A previous study, however, ${ }^{2}$ also examined normal thyroid, nodular goitre, and chronic thyroiditis and failed to find any vimentin staining of thyroid follicular cells. In contrast, we detected expression of vimentin in a wide range of thyroid samples, including examples of adenomas, thyroid hyperplasia, Hashimoto's thyroiditis and in normal thyroid tissue. The failure to detect such staining in the past may have been related to its focal nature and the use of immunofluorescence labelling, in which it is more difficult to assess the precise 


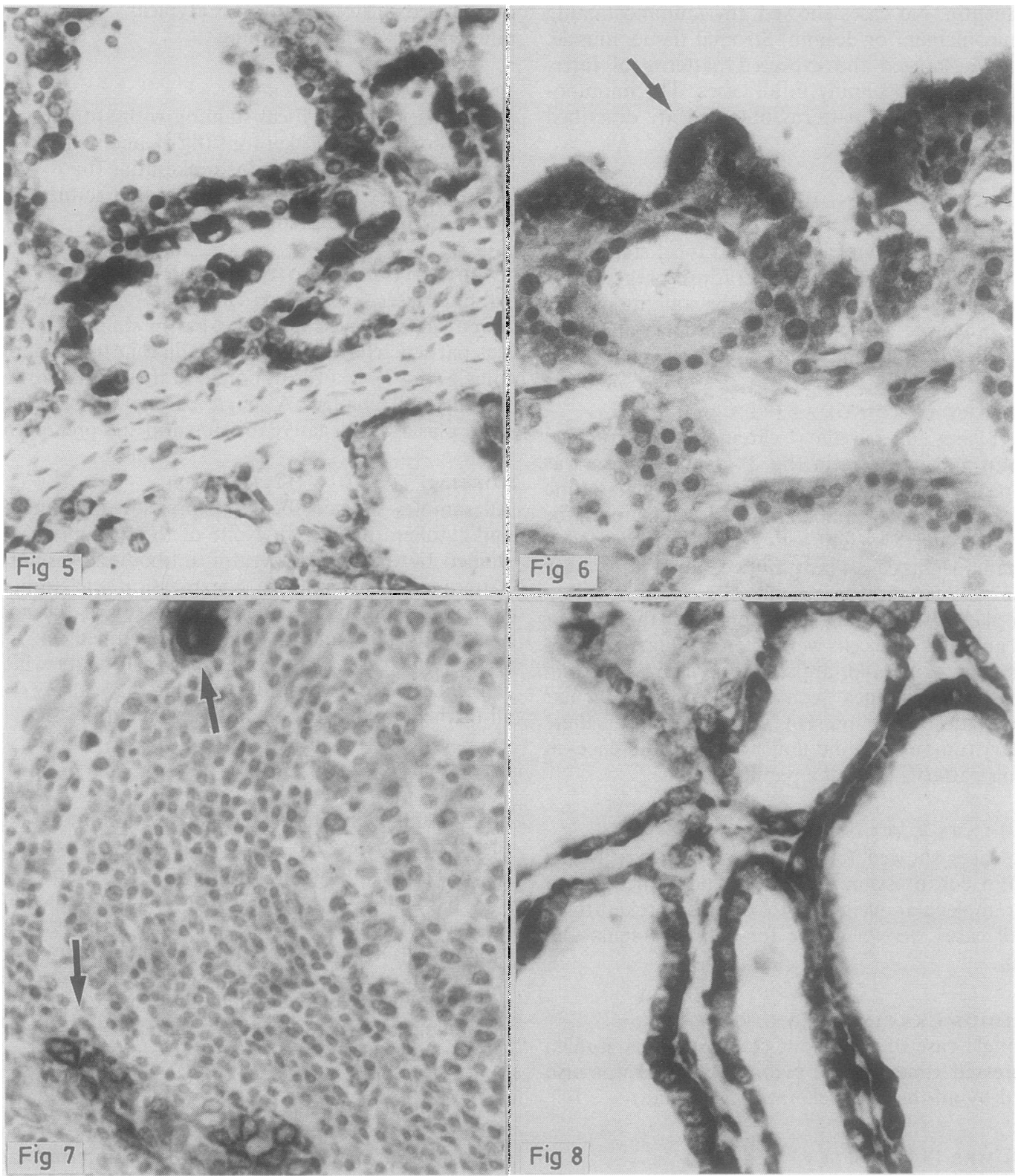

Fig 5 Vimentin expression in hyperplastic thyroid.

Fig 6 Prekeratin staining (PK121) in benign papillary protrusion in hyperplastic thyroid (arrow).

Fig 7 Prekeratin staining (PK63) in Hashimoto's thyroiditis immediately adjacent to and within lymphoid follicles (arrows).

Fig 8 Vimentin expression in normal thyroid gland.

All tissue stained by immunoperoxidase. 
localisation of staining than by immunoenzymatic techniques.

Our detection of coexpression in normal and benign thyroid samples indicates that this phenomenon, previously considered to be aberrant, is not an event exclusively associated with malignancy. Coexpression of vimentin and cytokeratin in normal tissue is not unprecedented in view of previous such findings in embryonic development ${ }^{29}$ and in myocardium and myometrium. ${ }^{30}$ Indeed, coexpression of two or more intermediate filament classes may be more common than is at present realised.

Expression of higher molecular weight cytokeratins (prekeratin) has been suggested as a useful and specific marker for malignant papillae in thyroid lesions and as a means of distinguishing between papillary and follicular carcinomas. ${ }^{2}$ Other authors, however, ${ }^{2} 3$ have noted staining of follicular carcinomas with prekeratin antibodies, and in one study more than half of the papillary carcinomas showed "minimal or no staining" with an antikeratin antibody. ${ }^{5}$

In our study, two of eight follicular carcinomas expressed prekeratins and four of 12 papillary carcinomas were unlabelled. The differences between the findings of these studies can be partly explained by the fact that cytokeratin is not a single antigen but a family of at least 19 different polypeptides, ${ }^{6}$ and antibodies used in different laboratories may thus differ considerably. In the present study we used four different monoclonal antibodies (PK52, 63, 121 and 141 ), which recognise higher molecular weight cytokeratins and should therefore be comprehensive in identifying these antigens in tissues. If this is accepted then our study does not substantiate the value of prekeratin as a marker for papillary carcinoma, particularly for its follicular variant, which has a better prognosis than true follicular carcinoma with which it may be confused. 4

We are also unable to support the suggestion ${ }^{2}$ that prekeratin can be used as a marker of malignant papillae in thyroid glands. In fact, the pattern of prekeratin expression in the thyroid seemed to be associated more with metaplastic than with neoplastic events, its distribution correlating closely with previous morphological descriptions of squamous and squamoid cells in the thyroid. ${ }^{31-33}$ These cells include those derived from ultimobranchial body and thyroglossal duct remnants, solid cell nests, and metaplastic follicular epithelium. In this study prekeratin expression was particularly noted around areas of inflammation in thyroiditis, within distorted trapped follicles in areas of fibrosis, and focally in papillary carcinomas, all of which are recognised sites of squamous metaplasia.

The final area of interest in this study was the apparent absence of neurofilaments in medullary carcinomas. A variety of neuroendocrine tumours, including islet cell tumours, some bronchial carcinoids, and small cell carcinomas of the lung, Merkel cell tumours of the skin and parathyroid adenomas express these intermediate filaments, ${ }^{134}$ in spite of the lack of neurofilament expression in normal neuroendocrine cells, including parafollicular thyroid cells. ${ }^{1}$ We were unable to detect neurofilament expression in several cases of formalin fixed and paraffin embedded medullary carcinoma. This suggests that these tumours may not have an entirely separate neuroendocrine histogenesis, a view recently advanced on the basis of morphology and the coproduction of thyroglobulin and calcitonin in thyroid carcinomas. ${ }^{35}$

We are grateful to Lesley Watts for typing the manuscript, to Sue Jones for technical help, and to $\mathrm{Dr}$ Karen Pulford for the use of the PK series of antibodies. KCG is a Wellcome Trust Senior Research Fellow in clinical science and holds the Gillson Scholarship of the Society of Apothecaries of London.

\section{References}

1 Miettinen M, Lehto V-P, Virtanen I. Antibodies to intermediate filament proteins in the diagnosis and classification of human tumours. Ultrastruct Pathol 1984;7:83-107.

2 Miettinen M, Franssila K, Lehto V-P, Paasivuo R, Virtanen I. Expression of intermediate filament proteins in thyroid gland and thyroid tumours. Lab Invest 1984;50:262-70.

3 Permanetter W, Nathrath WBJ, Lohrs V. Immunohistochemical analysis of thyroglobulin and keratin in benign and malignant thyroid tumours. Virchows Arch (Pathol Anat) 1982;398: 221-8.

4 Rosai J, Zampi G, Cargangiu ML. Papillary carcinoma of the thyroid: A discussion of its several morphological expressions with particular emphasis on the follicular variant. Am J Surg Pathol 1983;7:809-17.

5 Yagi Y, Yagi S, Saku T. The localization of cytoskeletal proteins and thyroglobulin in thyroid microcarcinoma in comparison with clinically manifested thyroid carcinoma. Cancer 1985; 56:1967-71.

6 Cooper D, Schermer A, Sun T-T. Classification of human epithelia and their neoplasms using monoclonal antibodies to keratins: strategies, applications and limitations. Lab Invest 1985;52:3:243-56.

7 Moll R, Franke W, Schiller D, Geiger B, Krepler R. The catalogue of human cytokeratins: patterns of expression in normal epithelia, tumours and cultured cells. Cell 1982;31:11-24.

8 Vickery A, Carcangiu M, Johannessen J, Sobrinho-Simoes M. Papillary carcinoma. Seminars in Diagnostic Pathology 1985; 2:90-100.

9 Hedinger C, Sobin LH. Histological typing of thyroid tumours. In: International histological classification of tumours. No. 11 . Geneva: World Health Organization, 1974.

10 Lang W, Georgii A, Stauch G, Kienzle E. The differentiation of atypical adenomas and encapsulated follicular carcinomas in the thyroid gland. Virchows Arch (Pathol Anat) 1980;385: $125-41$.

11 Harach $\mathrm{H}$. A study on the relationship between solid cell nests and mucoepidermoid carcinomas of the thyroid. Histopathology 1985;9:195-207.

12 Gatter KC, Falini B, Mason DY. The use of monoclonal anti- 
bodies in histopathological diagnosis. Rec Adv Histopathol 1984;12:35-67.

13 Cordell JL, Falini B, Erber WN, et al. Immunoenzymatic labelling of monoclonal antibodies using immune complexes of alkaline phosphatase and monoclonal antialkaline phosphatase (APAAP complexes). J Histochem Cytochem 1984;32: 219-29.

14 Makin C, Bobrow L, Bodmer W. Monoclonal antibody to cytokeratin for use in routine histopathology. J Clin Pathol 1984;37:975-83.

15 Viac J, Reano A, Brochier J, Staquet M-J, Thivolet J. Reactivity pattern of a monoclonal antikeratin antibody $(\mathrm{KL1})$. $J$ Invest Dermatol 1983;81:351-4.

16 Osborn M, Debus E, Weber K. Monoclonal antibodies specific for vimentin. Eur J Cell Biol 1984;34:137-43.

17 Gatter KC, Ralfkiaer E, Skinner J, et al. An immunocytochemical study of malignant melanoma and its differential diagnosis from other malignant tumours. J Clin Pathol 1985;38:1353-7.

18 van Muijen G, Ruiter J, Warnaar S. Intermediate filaments in Merkel cell tumours. Hum Pathol 1985;16:590-5.

19 Debus E, Weber K, Osborn M. Monoclonal antibodies to desmin, the muscle specific intermediate filament protein. $E M B O J$ 1983;21(12):2305-12.

20 Holthofer H, Miettinen A, Paasivuo R, et al. Cellular origin and differentiation of renal carcinomas: a fluorescence microscope study with kidney specific antibodies and lectins. Lab Invest 1983;49:317-26.

21 Caselitz J, Osborn M, Seifert G, Weber K. Intermediate sized filament proteins (prekeratin, vimentin, desmin) in the normal parotid gland and parotid gland tumours. Immunofluorescence study. Virchows Arch (Pathol Anat) 1981;393:273-86.

22 Rocca PJ, La Rheinwald JG. Coexpressin of simple epithelial keratins and vimentin by human mesothelioma and mesothelioma in vivo and culture. Cancer Res 1984;44:2991-9.

23 Osborn M, Altmannsberger M, Debus E, Weber K. Conventional and monoclonal antibodies to intermediate filament proteins in human tumour diagnosis. In: Cancer Cells: the transformed phenotype. New York: Cold Spring Harbor Laboratory, 1984:191-200.

24 Miettinen M, Lehto V-P, Virtanen I. Monophasic synovial sar- coma of spindle cell type. Epithelial differentiation as revealed by ultrastructural features, content of prekeratin and binding of peanut agglutinin. Virchows Arch (Cell Pathol) 1983;44: $187-99$.

25 Chase DR, Enzinger FM, Weiss SW, Langloss JM. Keratin in epithelioid sarcoma. An immunohistochemical study. Am $J$ Surg Pathol 1985;8:435-41.

26 Gatter KC, Dunnill MS, van Muijen GNP, Mason DY. Human lung tumours may coexpress different classes of intermediate filaments. J Clin Pathol 1986;39:950-4.

27 Theaker JM, Gatter KC, Esiri MM, Fleming KA. Epithelial membrane antigen and cytokeratin expression by meningiomas: an immunohistological study. J Clin Pathol 1986;39: 435-9.

28 Raemakers FCS, Haag D, Kont A, Maesker D, Jap PHK, Vooijs GP. Coexpression of keratin and vimentin type intermediate filaments in human metastatic carcinoma cells. Proc Natl Acad Sci USA 1983;80:2618-22.

29 Lowe EB, Hogan BLM, Kurkinen M, Garrels JI. Coexpressin of vimentin and cytokeratins in parietal endoderm cells of early mouse embryo. Nature 1983;303:701-4.

30 Huitfeld HS, Brandzaeg P. Various keratin antibodies produce immunohistochemical staining of human myocardium and myometrium. Histochemistry 1985;83:381-9.

31 Bullock W, Hummer G, Kahler J. Squamous metaplasia of the thyroid gland. Cancer 1952;5:966-74.

32 Harcourt-Webster JN. Squamous epithelium in the human thyroid gland. J Clin Pathol 1966;19:384-8.

33 LiVolsi V, Merino M. Squamous cells in the human thyroid gland. Am J Surg Pathol 1978;2:133-40.

34 Gould V. The coexpression of distinct classes of intermediate filaments in human neoplasms. Arch Pathol Lab Med 1985;109:984-5.

35 Sobrinho-Simoes M, Nesland JM, Johannesson JV. Farewell to the dual histogenesis of thyroid tumours. Ultrastruct Pathol 1985;8:2-3.

Requests for reprints to: Dr ID Buley, Nuffield Department of Pathology, John Radcliffe Hospital, Headington, Oxford OX3 9DU, England. 